\title{
Mine waste characterisation: the benefits of applying practical geological knowledge
}

\author{
G Wesley Mine Earth Pty Ltd, Australia \\ S Mackenzie Mine Earth Pty Ltd, Australia \\ G Campbell Graeme Campbell \& Associates Pty Ltd, Australia
}

\begin{abstract}
Mine waste characterisation involves the determination of the physical and geochemical character of waste rock (including fresh, transitional and oxide material). In many studies however, geological interpretation is rarely given sufficient consideration during both the sample selection and results interpretation stages, resulting in incomplete characterisation and potentially requiring additional sampling and testwork at a later date.

During the sample selection process, it is imperative that the most representative samples from all major rock types in a deposit are selected. To do so accurately, an understanding of the deposit morphology, genesis, alteration and structure is required. If these aspects are not well understood by the practitioner conducting sample selection, then important geological zones may not be represented in the set of selected samples, resulting in an invalid assessment. Conversely, site geologists may select appropriate and representative samples; however, the practitioner conducting the characterisation assessment may not fully appreciate the geological context of the materials being tested and miss potentially important intricacies in alteration and mineralogy, resulting again in an invalid or incomplete assessment.

Knowing how the major rock types from a deposit will typically behave from a physical perspective is important in providing management recommendations that complement the geochemical results. This applies especially to rock types within the fresh zone in terms of their competency and stability as candidate materials for sheeting and cladding of the outer slopes of waste landforms. Geological knowledge can aid in the selection of appropriate samples for various physical tests assessing the suitability of fresh zone rock units for erosion control over the longer term.

This paper explores the ways in which geological knowledge is intrinsically linked to technically sound mine waste characterisation; the starting point for pragmatic decision-making on waste rock management, waste rock dump design and closure.
\end{abstract}

Keywords: materials characterisation, geological assessment, waste rock, sample selection

\section{Introduction}

Mine waste characterisation involves the determination of the physical and geochemical character of waste rock (including fresh, transitional and oxide material); classifying material based on its potential to cause environmental harm or to affect the success of rehabilitation and closure. Mine waste materials identified as having deleterious properties often require specific management and placement within waste landforms to minimise impacts to the surrounding environment.

Mine waste characterisation studies can fail to give enough importance to geology when selecting samples and can focus solely on the raw results of analytical testwork; not considering them in the appropriate geological context of the deposit under consideration. The authors have worked on multiple projects where redrilling has been required either due to poor spatial representivity of data, insufficient sample numbers assayed, or an invalid interpretation of results in the context of deposit geology. Further examples are 
referenced in Mackenzie et al. (2016). Consequences of the insufficient characterisation of mine waste include the rejection of mining proposals and closure plans (leading to delays to project start-up), delays related to additional drilling and the repeat of characterisation assessments, and significant cost implications from delayed project approval or the rehandling of mine waste.

This paper explores how geological knowledge is intrinsically linked to mine waste characterisation and the benefits that can be achieved by properly applying this knowledge. The geological requirements as stated by relevant government guidelines will be outlined, followed by sections on the geochemical and physical assessment stages and the importance of geological interpretation. Case studies will be used within the assessment sections to provide examples on how geological information can be utilised.

\section{Mine waste characterisation and guidance}

Guidance for mine waste characterisation in Western Australia is provided by the Draft Materials Characterisation Guidelines (Department of Mines and Petroleum [DMP] 2016) issued by the Department of Mines, Industry Regulation and Safety. These guidelines are still in draft form and should be considered a basic framework that can be drawn upon to inform a mine waste characterisation process.

For materials characterisation, these guidelines state that a geological desktop study is prescribed as Phase 0 of the characterisation process, highlighting that understanding a deposit's geology is critical to proper mine waste characterisation. Geological interpretation is then used to inform drillhole selection for a Phase 1 screening and testwork stage that analyses the broad geochemical characteristics for a deposit using sulphur and multiple elements. The experience of specialised practitioners in geology, geochemistry and engineering assists the initial interpretation of information in the geological database for assessing Phase 1 outcomes. Phase 1 results then inform sample selection for a more detailed Phase 2 (and subsequent analytical stages) that comprehensively analyses geochemical, physical and mineralogical characteristics for representative samples.

Geologically, the guidance provided by DMP (2016) primarily focuses on two core points: sample selection should be conducted by someone familiar with the geological characteristics of the deposit, including lithology, structure, weathering, alteration and mineralisation; and samples should be representative for a deposit, considering spatial and vertical distribution and variability of geological units and material types.

Due to the complexity of many deposits, if proper geological interpretation and characterisation is not done correctly then zones of geochemical or physical significance could miss being identified and assessed, creating knowledge gaps that could present issues further along the mining process.

\section{Geochemical assessment}

The geochemical characterisation of a deposit primarily seeks to determine the acid-formation potential and metalliferous drainage risk for the chief waste rock lithologies and alteration styles within the regolith and bedrock profiles. DMP (2016) provides a basic framework for methodology within each Phase of investigation. The following methodology for Phase 0 to Phase 2 can be recommended as a standard approach that addresses the main geochemical requirements whilst still appropriately considering geology.

\subsection{Phase 0 desktop review}

An understanding of the deposit geology is imperative as it informs all following stages of sample selection. Understanding the geological characteristics assists in identifying zones within a deposit that have specific attributes that may otherwise be missed during sampling. Phase 0 is a pre-screening stage that reviews the available information for a deposit and provides a summary on its various characteristics, in addition to highlighting knowledge gaps. 
The Phase 0 desktop review should consist of the following:

- Review of relevant reports for information relating to background geology, mineralisation and alteration styles. Identify the dominant waste rock units, weathering and alteration types.

- Conduct a three-dimensional display and interrogation of the drillhole database with planned pit designs and lithological wireframes. Identify any trends or structurally significant zones where possible.

- Obtain volume estimates or lithological proportions for the deposit.

- Conduct an assessment on the physical stability expectations of the waste rock types.

- Interrogate assay database to determine the existing coverage of sulphur and other elemental assays.

- Identify knowledge gaps and highlight any zones where sample and assay information is incomplete.

- Select a number of spatially and lithologically representative drillholes that can be used for Phase 1 screening analysis and testwork.

\subsection{Phase 1 results review}

Phase 1 is a screening stage that assesses the geochemical nature of a project: assessing its basic acidformation potential, highlighting any elemental enrichment and allowing for the targeted sampling of zones that require further assessment.

The Phase 1 results review stage should consist of the following:

- If required, develop a Phase 1 Sampling and Analysis Plan for representative drillholes selected during Phase 0.

- Conduct static testwork on the samples for sulphur and other elements to provide insight into internal lithological variability and to act as a screening stage for Phase 2 analysis.

- Conduct basic acid-base accounting on available Phase 1 geochemical results if carbon data is available.

- Create a three-dimensional display and interrogation of the Phase 1 results in relation to the deposit morphology and genesis. This can be useful when an entire drilling database is being utilised for Phase 1 analysis.

- Identify any areas of geological/geochemical variability internally within rock types.

- Identify both geochemically representative and anomalous zones for all rock types.

- Develop a Phase 2 Sampling and Analysis Plan that will be used for more detailed and targeted testwork.

To provide a comprehensive analysis, the Phase 1 sulphur and multi-elemental results (be they from within the database or from purpose-drilled holes) should ideally consist of continuous, downhole samples over the length of each drillhole. Having a continuous set of downhole results (versus discrete, disparate samples) allows for the identification of any trends across the spatial extents of the rock and alteration types.

Once there is confidence that the assay database for the project is spatially and lithologically representative and complete (after any required additional sampling), analysis of the sulphur, acid-base accounting and elemental enrichment can be commenced.

Sulphur is one of the key elements assessed during Phase 1 as it can be used as a conservative proxy for sulphide-sulphur (under the assumption that all sulphur is present as pyrite) during Phase 1 analysis. Further details on this process and its implications for Acid and Metalliferous Drainage can be found in references such as Smart et al. (2002), International Network for Acid Prevention (2014) and Price (2009). 
Available multi-element data is also reviewed during this Phase to highlight additional areas requiring further investigation during Phase 2 analysis.

The interrogation of the data from the Phase 1 analyses should complete the background knowledge of the deposit geology, as it will provide a broad overview of the deposit structure, lithology, internal variability and general geochemical variation.

\subsection{Phase 2 results review}

The Phase 2 results review stage should consist of the following:

- Selection of a targeted subset of samples available from Phase 1, representative of all rock and weathering types at the deposit.

- Detailed static testwork (and follow-up kinetic testwork if required) to analyse the geochemical character of samples. Tests can include (but are not limited to) net acid producing potential, net acid generation, acid neutralising capacity, sulphur and carbon speciation and water extractability.

- Mineralogical analysis to increase confidence in physical stability estimates from Phase 0 and to aid in the geochemical evaluation of samples.

- Link results back to the Phase 1 dataset to determine zones of significance.

- Development of management recommendations for all waste rock types.

The Phase 2 analysis investigates in detail the geochemical character of various lithologies and alteration zones from the deposit and identifies any rock units and mineralogy that may have beneficial or deleterious properties.

The findings from the detailed Phase 2 assessment should be linked back to the more extensive Phase 1 dataset, to better model the areas of influence and volumes of these zones of significance. This facilitates development of material management recommendations for the mining stages.

\subsection{Case study: Phase 1 sulphur and structural knowledge}

This case study describes the baseline waste characterisation assessment undertaken for a deposit in the early stages of exploration and interpretation. This was a shallow-dipping, stratigraphically hosted deposit in the Pilbara region of Western Australia.

\subsubsection{Phase 1 statistics}

The Phase 1 study of the geochemical database assessed the concentration and distribution of sulphur across all lithologies (3,721 samples across continuous, downhole intervals); plotted in histogram format in Figure 1. A distinct population of sulphur results $>1.0 \%$ was identified at the deposit (illustrated by the red circle in Figure 1). Results above this percentage can be considered elevated and, save for quite calcareous lithologies, have the potential to acidify upon exposure and weathering.

The distribution of sulphur results between the various lithologies at the deposit was then reviewed to identify whether specific rocks were hosting the elevated sulphur. Figure 2 shows that though the majority of results $>1 \%$ sulphur were hosted by the dominant lithologies at the deposit (sediments and mafics), these elevated sulphur assays were not exclusive to these rock types. 


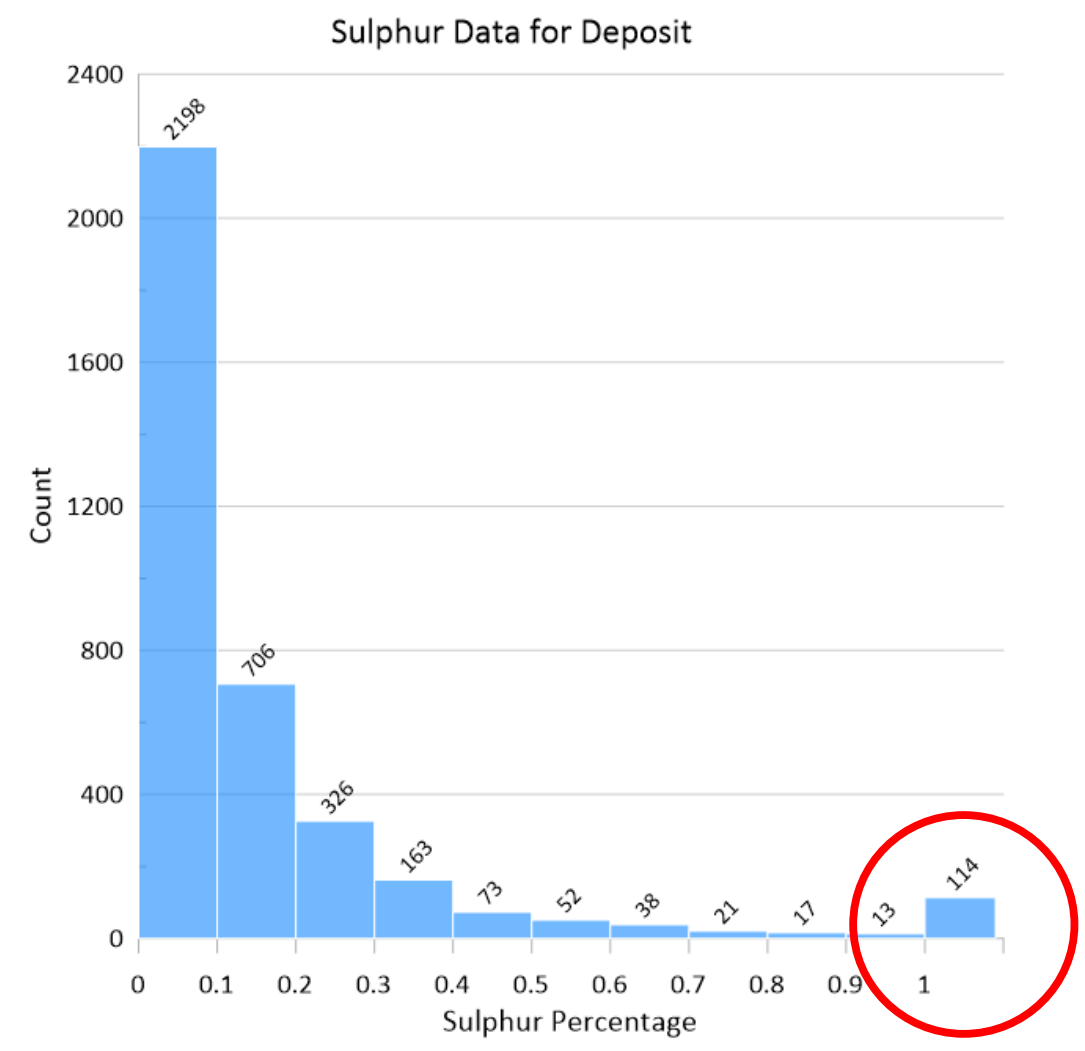

Figure 1 Sulphur distribution for the entire deposit (red circle highlights sulphur concentrations above 1\%)

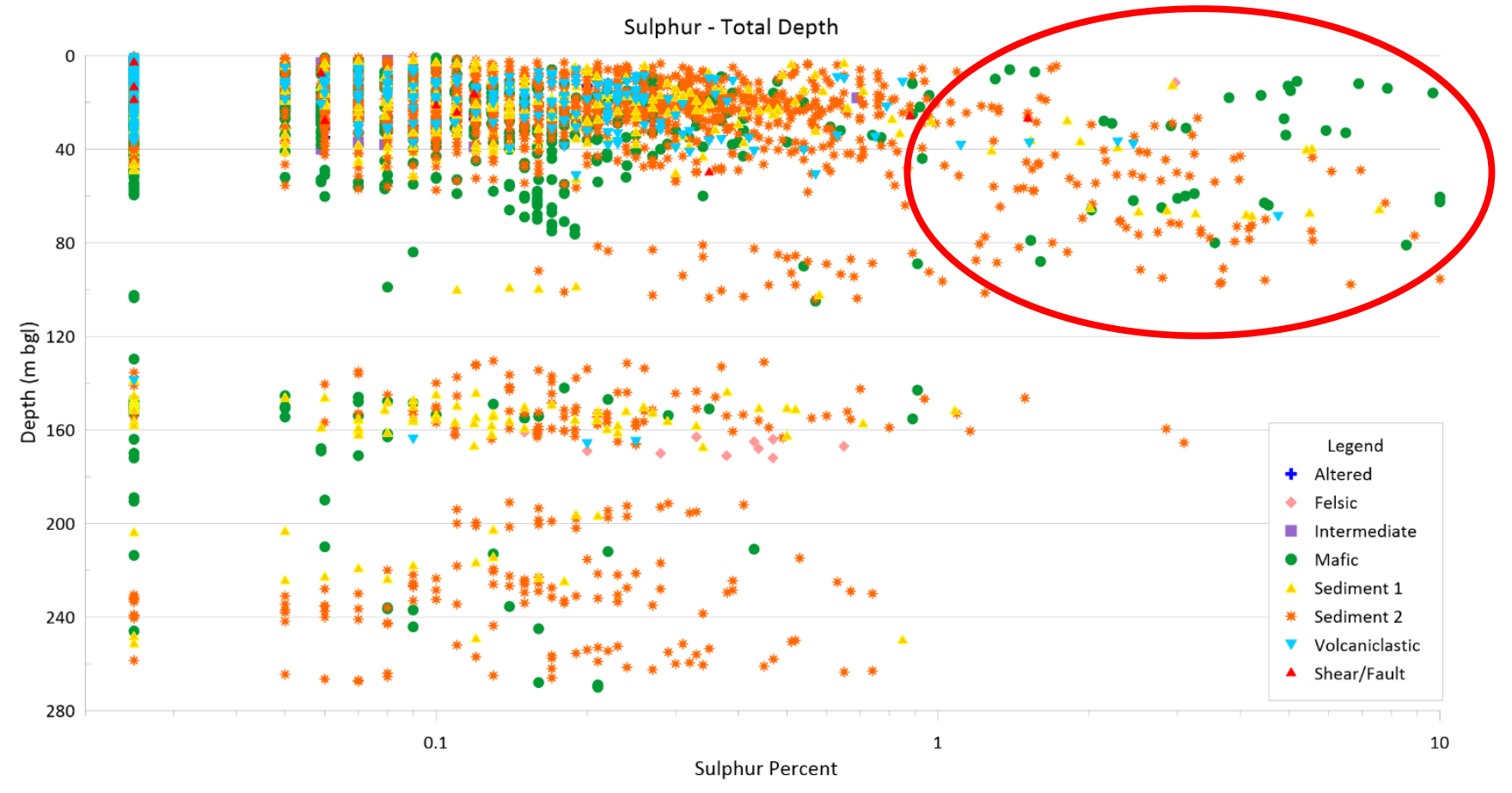

Figure 2 Sulphur distribution and depth downhole, subdivided by rock type at the deposit (red circle highlights sulphur concentrations above $1 \%$ ) 


\subsubsection{Phase 1 statistics incorporating geological interpretation}

To analyse the spatial distribution of the elevated sulphur, the results were plotted on the detailed geological map for the deposit (Figure 3). This map highlighted the presence of a sulphidised fault complex in the centre of the deposit that was found to encapsulate a high number of the Phase 1 sulphur-enriched samples.

All samples within this fault complex could then be isolated from the dataset and studied separately.

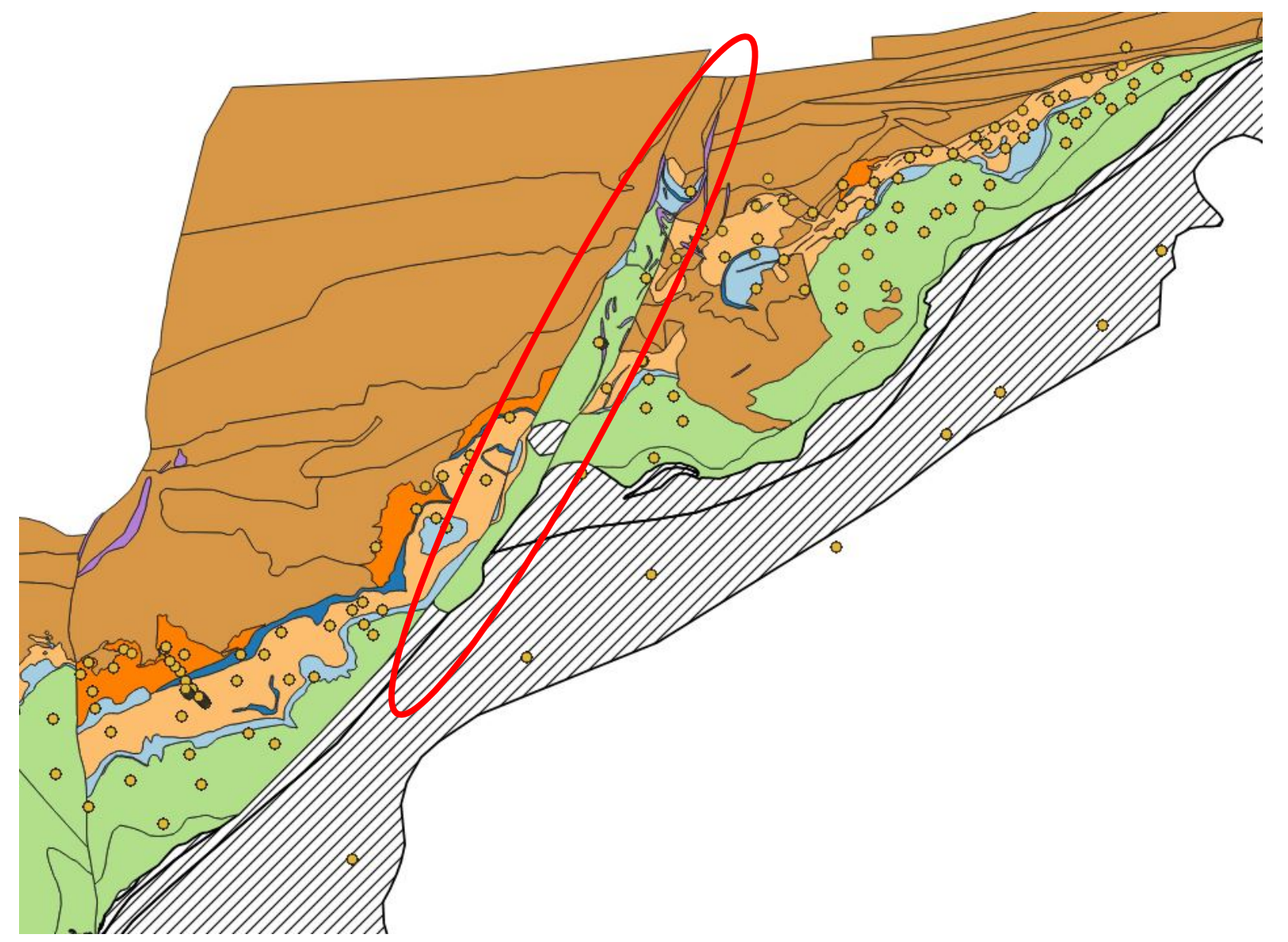

Figure 3 Updated geological map showing the location of the new fault complex (in red)

The high-sulphur fault data accounted for $75 \%$ of the sulphur levels $>1 \% \mathrm{~S}$ for the deposit (Figure 4). By excluding this high-sulphur fault data (effectively outlier data when viewed in terms of the deposit-wide database), the occurrence of sulphur levels $>1 \%$ in the remaining dataset reduced considerably. This finding allowed for the geochemistry of the fault complex to be analysed in isolation, without the very high sulphur levels influencing geochemical decisions for the rest of the deposit. Options for this sulphur-elevated fault zone could be to avoid it completely during mining (via mine plan modification) or to quantify its volume and schedule its isolation by burial within the waste dump design. Based on the geochemical findings, it is most likely that this zone at the deposit will not be developed during mining.

This example highlights the importance of knowing as much information about a deposit's geology as possible as it can have a significant bearing on how the results of geochemical assessments are accommodated in the decision-making processes for overall waste rock management. 


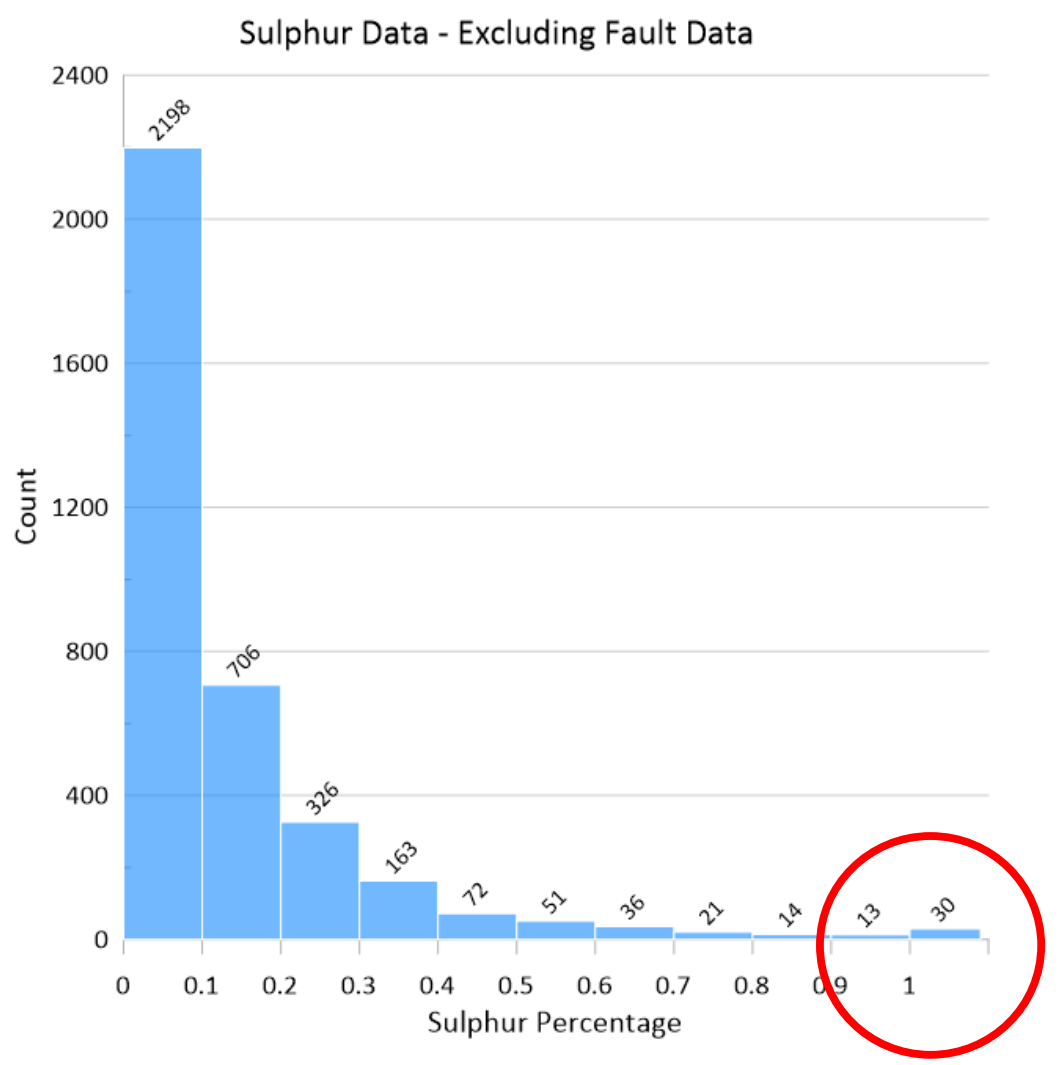

Figure 4 Sulphur distribution across all rock types at the deposit, excluding fault data (red circle highlights sulphur concentrations above 1\%)

\section{$4 \quad$ Physical assessment}

Knowing how the major mine waste units will behave from a physical perspective is important in determining their erosional stability properties (i.e. their ability to resist erosion) for landform design requirements, to complement the geochemical results, and to inform waste management recommendations. Ideally, fresh, physically durable (i.e. resistant to deformation) and geochemically stable and benign waste rock units would be utilised to armour/clad the outer slopes of waste rock dumps and tailings storage facilities at decommissioning. Identifying sources of suitable rock early in the mining process allows for the adjustment of mining plans and, where required, segregation of inert, durable rock to reduce erosion risks for decommissioned landforms.

Regarding the rehabilitation profiles of the outer slopes on landforms at decommissioning, physical stability against erosion is crucial and may be achieved through the incorporation of inert, fresh waste rock into the finished surface established during reshaping, sheeting and recontouring of the final landforms. The resulting rehabilitation profiles thus comprise a spatially varying mixture of topsoils and fresh rock. Duricrusts and lateritic surficial materials stockpiled during pre-stripping works may also be included in the mixed rehabilitation profiles, as appropriate. The resulting rehabilitation profiles correspond to a clast-supported matrix.

Central to this outer slope rehabilitation approach is establishing potential sources of suitable inert rock to be segregated, as needed, during mining for landform decommissioning and other site-wide applications (e.g. construction of open pit abandonment bunds). Sampling and testing of representative samples of fresh waste rock is therefore required as part of this assessment, with the application of geological knowledge expediting this task.

Most waste characterisation studies frequently determine the physical characteristics of surficial mine waste units, though they focus mainly on the more weathered components within the upper-most section of the 
geological profile. Testing samples of such surficial units for plant-growth characteristics is undertaken in the context of revegetation and rehabilitation programmes. The physical stability characteristics of the fresh rock component in most waste characterisation studies is often not given much consideration, with most presenting the conclusion that all fresh waste is considered equal for armouring purposes.

Whilst fresh rock might generally be considered more physically stable than weathered rock materials, this is not always the case. Various fresh rock types that appear durable and coherent following excavation, can rapidly degrade into soil-like material (residual mineral grains) within years to decades (e.g. shales, mudstones, certain ultramafics), even under the strongly arid conditions like those within the Australian interior.

The following methodology for Phase 0 is introduced as a method by which the physical stability of fresh waste rock can be inferred based on the geological characteristics of a deposit. These inferences can then be supported by follow-up testwork during later phases where required. This methodology can help in identifying potential sources of waste rock for cladding/armouring applications that can be incorporated into the rehabilitation profiles of the final outer slopes of waste landforms, as outlined above. It can also be used to identify potential sources of low permeability materials for the development of a purpose-built cover.

\subsection{Phase 0 desktop review}

Knowledge of the typical weathering and erosional behaviours of rock types, taking various geological factors into account, often allows for the early identification of potentially problematic lithologies. This type of review must be conducted by a geologist familiar with the erosional behaviour of mined rock (blasted/excavated/transported/dumped).

The rock type, mineralogy, alteration style and structural deformation of a rock are all important factors to consider during an assessment of the erosional stability. It is important that all factors be considered conjointly as there are complex interactions between them that combine to dictate what the final durability of a rock type will be.

Physically, the assessment of the constituent mineral proportions and their Mohs hardness (a scale for rating mineral hardness) can provide an indication of base physical durability of a given rock type (Mackenzie et al. 2016). This is especially applicable for many igneous and metamorphic rocks where the dense crystal structure was formed under intense pressure, rendering them highly durable (for examples, granite and syenite). Consideration should be given to the type of rock within which the minerals are contained, as rock texture (e.g. massive, laminar and bedded) and the crystal habit of minerals (e.g. cubic, orthorhombic and monoclinic) also affect how the rock will behave when placed under physical stress (e.g. striking, crushing).

The degree of structural deformation must also be considered as strong shearing or faulting can create planes of weakness and pathways for both fluid ingress and structural cleaving. Fine-scale laminar bedding in sedimentary rocks can also provide similar conditions for fluid access. Alteration styles such as intense silicification can strengthen a rock; however, other styles such as magnetite-actinolite alteration may make a rock brittle and talc-carbonate alteration (often encountered in shear zones within ultramafics) can cause a rock to be very soft and friable. The use of core photos and analysis of the weathering degree and Rock Quality Designation (i.e. the degree of fracturing in core (Deere \& Deere 1988)), is often very useful in supporting these initial estimations.

Chemically, a primary mineral's response to the weathering environment depends chiefly on its crystal structure and composition (Scott \& Pain 2009). The crystal structure of silicate minerals plays a large part in their solubility, as layer silicates (such as micas, chlorite, kaolinite and smectites) have planar crystal lattices that allow for greater interaction with dissolving fluids versus other silicate forms (Scott \& Pain 2009).

Solubility rates have been variably studied in the literature under controlled laboratory conditions (White \& Brantley 1995) and thus allow an indicative assessment of the relative rates of hydrolysis and dissolution as a function of physio-chemical variables, such as $\mathrm{pH}$, temperature, and solution ionic strength (salinity). Geologists have long used the Goldich dissolution series (and extensions of it) as a basis to identify a mineral's 
solubility under generally neutral conditions (as incorporated in Scott \& Pain (2009)). As minerals are most stable under conditions that are closest to those at their formation, minerals that form at higher temperatures and pressures are less stable at surficial conditions than are those formed at lower temperatures and pressures. This means that minerals such as olivine (high-temperature) will weather more quickly than quartz (low-temperature). Given that the Goldich series includes approximately only 12 of the common rock-forming minerals, further literature and research must be consulted by practitioners to ascertain the behaviour of other rock-forming minerals, as numerous studies have progressively updated and modified the Goldich series. The rationalisation of relative dissolution rates (under ambient conditions applicable to field weathering) and the connectivity of structural silicon and oxygen atoms within the crystal structures of silicate and aluminosilicate groups of minerals is outlined in White \& Brantley (1995). However, such connectivity is not the only factor controlling relative dissolution rates.

Knowledge of source rock mineralogies also enables the estimation of weathering products and can anticipate whether smectites and other swelling clays may form. The presence of these clay types can severely weaken and even fracture rock (depending on their proportion) as they swell during wet events and shrink upon subsequent drying. Knowledge of the presence of these clays is critical as it has implications regarding recommendations for longer-term waste rock management and waste landform design. If smectitic clays are present, it is generally advised to encapsulate this material within waste rock dumps.

\subsection{Case study: Comparison of weathering rates on rock types}

As an example of how rapidly various rock units can weather over comparatively short time scales (decadal), Figure 5 shows drillcore from a mine in the Kimberley that was left uncovered and exposed to rainfall over a 10 -year period. The tray of core as initially photographed at the time of drilling contained both quartzite and mudstone. After a decade of being exposed, the quartzite remained comparatively unchanged, whereas the mudstone has degraded into highly erodible material comprising gravels, sands, silts and clays. Due to the conditions of storage in a core tray, these rock types have been subjected to temperature variations (thermal expansion and contraction), wetting/drying cycles and associated geochemical weathering.

The quartzite would be rated as high stability as it is a metamorphic rock that contains a very high proportion (>90\%) of quartz cemented by silica (Bonewitz 2012). Quartz displays a high Mohs hardness at seven and a high resistance to solubility. In combination, these factors provide quartzite with a high physical and chemical stability.

The mudstone would be rated as low stability as it is a very fine-grained sedimentary rock that tends to contain high proportions of clay-sized particles comprised of various proportions of quartz, feldspar, mica, chlorite, carbonate and clay minerals (Scott \& Pain 2009). Clay minerals (e.g. kaolinite), muscovite, chlorite and carbonates all typically display low Mohs hardness (<3) (Bonewitz 2012), whilst the quartz and feldspar are stronger (6-7 hardness). The dominance of the softer minerals suggests that the mudstone would have a low to variable physical durability. The very fine grain size $(<32 \mu \mathrm{m})$ and micro-laminar bedding will provide a high surface area and fluid pathways for dissolving fluids to access and interact with the constituent primary particles. The combination of these factors results in the comparatively rapid degradation of the mudstone. 

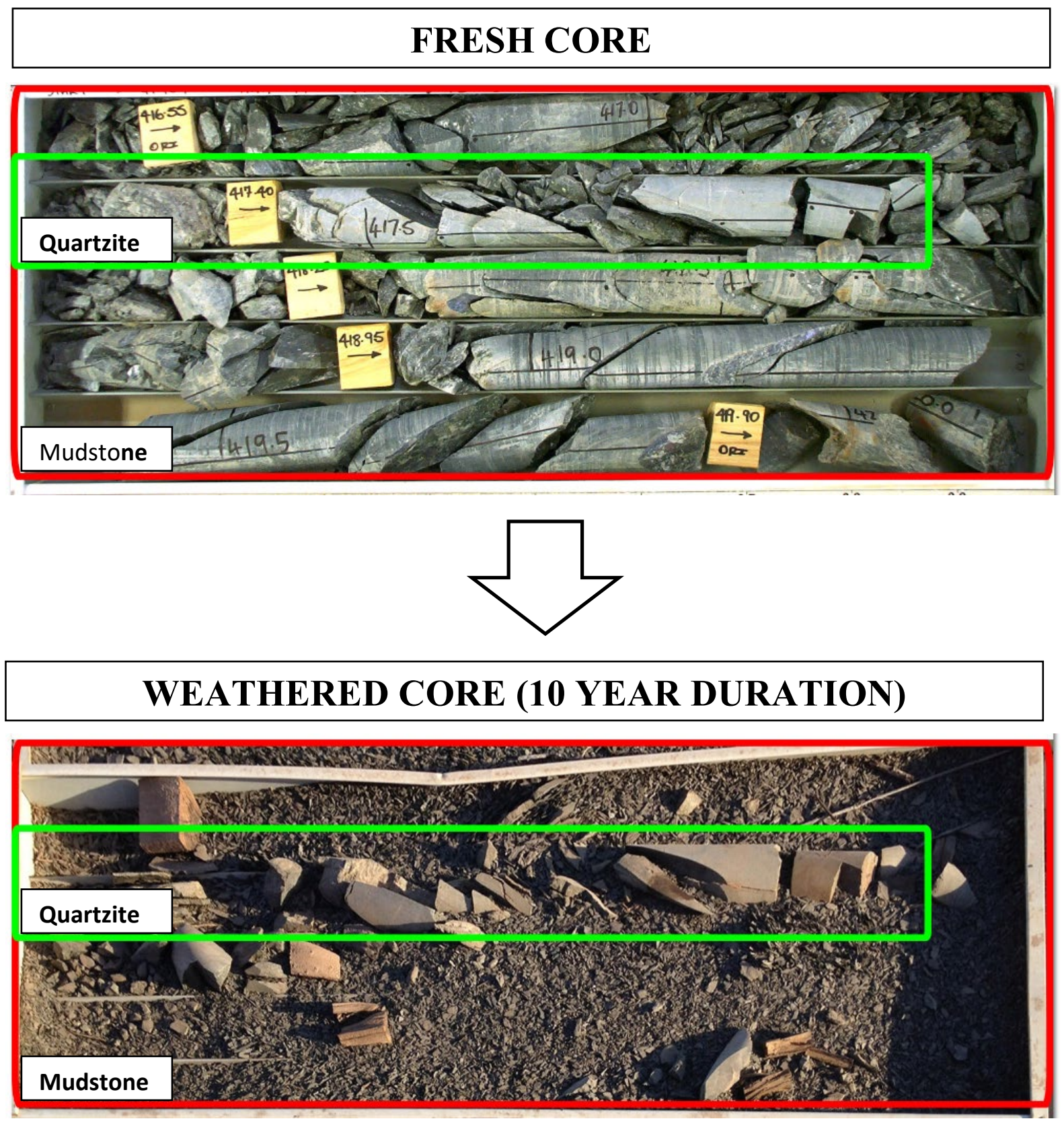

Figure 5 Drillcore showing the rapid physical breakdown of mudstone following a decade of exposure

\section{Conclusion}

The application of practical geological knowledge is critical for effective mine waste characterisation. Prior to the commencement of any characterisation program, an accurate geological interpretation for a deposit should ideally be provided. Aside from lithologies, the interpretation for a deposit should also take into consideration of all major mineralisation, structural, weathering and alteration styles present.

Using this geological model as a base, a Phase 1 dataset can be obtained and analysed, informing the selection of representative samples for Phase 2 (and further) analysis.

It is imperative that the geological knowledge of a deposit is known as potential errors in sample selection and data interpretation can occur where this is lacking. Upon the review of a geochemical characterisation assessment, if the samples selected are found not to be representative of a deposit's geology, information gaps would be created that could have been avoided if a robust geological model was present from the 
outset. This has been observed by the authors on multiple projects where proponents have been required by regulators to resample, and even redrill, deposits after submitting a waste characterisation assessment due to incorrect or insufficient information. This then has implications for project approval and can cause significant delays for the commencement of mining.

The assessment of physical characteristics for a project's waste rock is necessary, both for determining suitable sources of armouring material for the exterior of waste rock dumps and for identifying dispersive or erodible material that may compromise these dump surfaces.

Practical geological knowledge can be used to estimate the physical character and likely erodibility of waste rock types based on characteristics such as lithology, mineralogy, alteration style and degree of structural deformation. Knowing how the major rock types from a deposit will typically behave from a physical perspective is important in providing management recommendations that complement the geochemical results.

Knowledge of deposit geology is intrinsically linked to successful mine waste characterisation and subsequent mine waste management. Though there are many stages that involve complexity, if the practitioner conducting the mine waste characterisation is experienced in geology then the correct geological context for the sampling program and interpretation of results can be applied, leading to the development of much more robust and accurate recommendations.

\section{References}

Bonewitz, RL 2012, Nature Guide: Rocks and Minerals, Dorling Kindersley, New York.

Deere, DU \& Deere, DW 1988, 'The rock quality designation (RQD) index in practice', in L Kirkaldie (ed.), Rock Classification Systems for Engineering Purposes, ASTM International, West Conshohocken, pp. 91-101.

Department of Mines and Petroleum 2016, Draft Guidance: Materials Characterisation Baseline Data Requirements for Mining Proposals, Department of Mines and Petroleum, East Perth, viewed 1 August, 2019, http://www.dmp.wa.gov.au/ Documents/Environment/ENV-DraftGuideance_MaterialsCharacterisationDataProposal.pdf

International Network for Acid Prevention 2014, Global Acid Rock Drainage Guide, Mitcham, viewed 1 August 2019, http://www.gardguide.com/images/5/5f/TheGlobalAcidRockDrainageGuide.pdf

Mackenzie, S, de Kever, N, Smedley, E \& Gregory, S 2016, 'Mine waste characterisation: complexities with assessing the physical properties of rock', in AB Fourie \& M Tibbett (eds), Proceedings of the 11th International Seminar on Mine Closure, Australian Centre for Geomechanics, Perth, pp. 677-690.

Price, WA 2009, Prediction Manual for Drainage Chemistry from Sulphidic Geologic Materials, Mine Environment Neutral Drainage Program, viewed 1 August 2019, http://mend-nedem.org/wp-content/uploads/1.20.1_PredictionManual.pdf

Scott, KM \& Pain, CF 2009, Regolith Science, CSIRO Publishing, Collingwood.

Smart, R, Skinner, B, Levay, G, Gerson, A, Thomas, J, Sobieraj, H, Schumann, R, Weisener, C, Weber, P, Miller, S \& Stewart, W 2002, ARD Test Handbook, AMIRA International, Melbourne, viewed 1 August 2019, http://www.amira.com.au/documents/ downloads/P387AProtocolBooklet.pdf

White, AF \& Brantley, SL (eds) 1995, 'Chemical weathering rates of silicate materials', Reviews in Mineralogy and Geochemistry, vol. 31. 
